\title{
The $\alpha_{2}$-adrenoceptors of the human retinoblastoma cell line (Y79) may represent an additional example of the $\alpha_{2 \mathrm{C}}$-adrenoceptor
}

\author{
${ }^{1}$ Marie M. Gleason \& ${ }^{2} \mathrm{~J}$. Paul Hieble \\ Department of Pharmacology, SmithKline Beecham Pharmaceuticals, King of Prussia, PA 19406, U.S.A.
}

1 In agreement with the literature, correlation of the ability of a series of agonists and antagonists to displace $\left[{ }^{3} \mathrm{H}\right]$-rauwolscine binding shows the $\alpha_{2}$-adrenoceptors of HT29 cells, NG108-15 cells, OK cells and homogenates of rat sublingual gland to represent four distinct subtypes.

$2\left[{ }^{3} \mathrm{H}\right]$-rauwolscine also bound with high affinity $\left(K_{\mathrm{D}}=0.30 \pm 0.10 \mathrm{mM}\right)$ to a human retinoblastoma cell line (Y79). Specific binding represents $73 \%$ of total binding, and a $B_{\max }$ of $38 \pm 1 \mathrm{fmol} \mathrm{mg}^{-1}$ protein was determined.

3 Correlation of antagonist affinities against $\left[{ }^{3} \mathrm{H}\right]$-rauwolscine with corresponding values in the other four tissue sources showed the Y79 cells to resemble most closely the OK cells, the prototype example of an $\alpha_{2 \mathrm{C}}$-adrenoceptor, with a correlation coefficient of 0.90 and a regression slope of 1.01 being obtained for 10 antagonists in these two systems.

4 Comparison of $K_{\mathrm{D}}$ values for $\left[{ }^{3} \mathrm{H}\right]$-rauwolscine also showed a similarity between the $\mathrm{OK}$ cells $(0.19 \pm 0.07 \mathrm{nM})$ and Y79 cells.

5 These data suggest that the human retinoblastoma cell line may represent an additional example of the $\alpha_{2 \mathrm{C}}$-adrenoceptor subtype.

Keywords: HT29 cells; NG108-15 cells; rat sublingual gland; $\left[{ }^{3} \mathrm{H}\right]$-rauwolscine; $\alpha_{2}$-adrenoceptor subtypes

\section{Introduction}

In the past few years, several groups have succeeded in cloning and expressing $\alpha_{2}$-adrenoceptors from rat, human and porcine sources (Lorenz et al., 1990; Guyer et al., 1990; Weinshank et al., 1990; Flordellis et al., 1991; Harrison et al., 1991; Chhajlani et al., 1991; Voigt et al., 1991; Lanier et al., 1991). From these molecular biological studies, it is clear that there are at least three $\alpha_{2}$-adrenoceptor subtypes, having distinct amino acid sequences. However, it is not yet clear whether the three $\alpha_{2}$-adrenoceptor proteins isolated from rat correspond to the three isolated from human sources (Harrison et al., 1991) or whether a fourth subtype has been cloned from the rat genomic library (Lanier et al., 1991). Likewise, assignment of the cloned receptor proteins to the multiple $\alpha_{2}$-adrenoceptor subtypes which have been identified by radioligand binding asays (Bylund, 1988; Uhlen \& Wikberg, 1991) is still controversial.

Binding sites defined as $\alpha_{2}$-adrenoceptors, based on their high affinity for $\left[{ }^{3} \mathrm{H}\right]$-rauwolscine, can be unequivocally subclassified into the $\alpha_{2 A^{-}}$and $\alpha_{2 B^{-}}$-adrenoceptor subgroups, based on high $\left(\alpha_{2 B}\right)$ or low $\left(\alpha_{2 A}\right)$ affinity for prazosin or ARC-239. Multiple examples of both $\alpha_{2 A^{-}}$and $\alpha_{2 B}$-adrenoceptors are known, both in tissue culture lines and in tissue homogenates from several species. Functional studies measuring the ability of prazosin and ARC-239 to inhibit adenylate cyclase activation by an $\alpha_{2}$-adrenoceptor agonist in HT29 $\left(\alpha_{2 \mathrm{~A}}\right)$ and NG108-15 $\left(\alpha_{2 B}\right)$ cells support this subclassification scheme (Bylund \& Ray-Prenger, 1989). Cloned and expressed $\alpha_{2-}$ adrenoceptor proteins can also be divided into two groups, having either high $(<100 \mathrm{nM})$ or low $(>1000 \mathrm{nM})$ affinity for prazosin (Simmoneaux et al., 1991; Harrison et al., 1991; Lanier et al., 1991).

\footnotetext{
${ }^{2}$ Author for correspondence at: SmithKline Beecham Pharmaceuticals, Department of Pharmacology, UW2510, P.O. Box 1539, King of Prussia, PA 19406-0939, U.S.A.

${ }^{1}$ Present address: Rhone-Poulenc Rorer, 500 Avida Drive, Collegeville, PA 19426, U.S.A.
}

When the ability of a diverse series of antagonists to inhibit $\left[{ }^{3} \mathrm{H}\right]$-rauwolscine binding was compared in a variety of tissues, it became apparent that there were more than two $\alpha_{2}$-adrenoceptor binding sites. It is currently thought that at least four $\alpha_{2}$-adrenoceptors can be identified by this technique (Bylund, 1988; Blaxall et al., 1991; Simmoneaux et al., 1991). The two additional sites have been designated as $\alpha_{2 \mathrm{C}}$ and $\alpha_{2 \mathrm{D}}$. Although the $\alpha_{2 \mathrm{C}}$ and $\alpha_{2 \mathrm{D}}$ sites resemble the $\alpha_{2 \mathrm{~B}}$ and $\alpha_{2 \mathrm{~A}}$, respectively, antagonists capable of differentiating the four sites are available (Blaxall et al., 1991). By examining the simultaneous interactions of several antagonists at the $\alpha_{2}$ adrenoceptor binding site it may be possible to identify even more discrete binding sites (Uhlen \& Wikberg, 1991).

The $\alpha_{2 \mathrm{C}}$-adrenoceptor has only been identified thus far in the OK cell line, derived from the opossum kidney, and in tissue homogenates prepared from fresh opossum kidneys (Blaxall et al., 1991), and it has been suggested that the $\alpha_{2 \mathrm{C}}$ and $\alpha_{2 \mathrm{~B}}$-adrenoceptors might represent species variants (Lorenz et al., 1990). Hence the demonstration of an $\alpha_{2 C}$ site in another tissue source, not derived from the opossum, would strengthen the case for its role as a distinct $\alpha_{2}$-adrenoceptor subtype. In this report, we compare the ability of a series of 10 antagonists to inhibit the binding of $\left[{ }^{3} \mathrm{H}\right]$-rauwolscine to membrane homogenates from five tissues/cell lines. Tissues examined include known examples of $\alpha_{2 A}$ (HT29 cells), $\alpha_{2 B}$ (NG108-15 cells), $\alpha_{2 C}$ (OK cells) and $\alpha_{2 D}$ (rat sublingual gland), as well as a human derived retinoblastoma cell line (Y79; Reid et al., 1974). Y79 cells have been shown to have $\alpha_{2}$-adrenoceptors, which were suggested to be of the $\alpha_{2 \mathrm{~A}}$ subtype (Kazmi \& Mishra, 1989).

\section{Methods}

\section{Cell culture}

HT29 cells (American Type Culture Collection (ATCC), Rockville, MD, U.S.A.) and OK cells (kindly donated by $\mathrm{Dr}$ 
D.B. Bylund, University of Nebraska, Omaha, NB, U.S.A) were grown in Dulbecco's modified Eagle's medium (DMEM) containing high glucose and supplemented with $10 \%$ foetal bovine serum (FBS). NG108-15 cells (kindly donated by $\mathrm{Dr}$ Marshall Nirenberg, National Institutes of Health, Bethesda, MD, U.S.A.) were grown in DMEM supplemented with $10 \%$ FBS, $0.1 \mathrm{mM}$ hypoxanthine, $0.4 \mu \mathrm{M}$ aminopterin and $16 \mu \mathrm{M}$ thymidine. Y79 cells (ATCC) were grown in suspension in RPMI 1640 medium supplemented with $15 \%$ FBS. To obtain cells for tissue preparation, HT29 and OK cells were subcultured with $0.05 \%$ trypsin containing $0.53 \mathrm{mM}$ ethylenediaminetetraacetic acid (EDTA), and NG108-15 cells were gently agitated loose from the culture flask. Cells were maintained in a humidified atmosphere consisting of $5 \% \mathrm{CO}_{2}$ : $95 \%$ air $\left(10 \% \mathrm{CO}_{2}: 90 \%\right.$ air for NG108-15) and harvested for membrane preparation after reaching confluence.

\section{Tissue preparation}

Cells were scraped, pelleted by centrifugation $(300 \mathrm{~g}, 5 \mathrm{~min})$ and washed twice in Dulbecco's phosphate buffered saline (composition in $\mathrm{mM}: \mathrm{KCl} 2.7, \mathrm{KH}_{2} \mathrm{PO}_{4} 1.5, \mathrm{NaCl} 137$ and $\mathrm{Na}_{2} \mathrm{HPO}_{4}$ 8.1). The $\mathrm{pH}$ of this solution was 7.2. The cell pellet was resuspended in ice-cold $5.0 \mathrm{mM}$ Tris, $1.0 \mathrm{mM}$ EDTA, pH 7.4, and homogenized on ice with a polytron (Brinkman, Westbury, NY, U.S.A.) $(3 \times 15 \mathrm{~s}$ burst on setting 6). The homogenate was centrifuged $(500 \mathrm{~g}, 5 \mathrm{~min})$. The supernatant was collected and centrifuged at $100,000 \mathrm{~g}$ for $30 \mathrm{~min}$. The resulting membrane pellet was resuspended in $25 \mathrm{mM}$ glycylglycine, $\mathrm{pH} 7.6$, and frozen at $-70^{\circ} \mathrm{C}$ following protein determination.

Rat sublingual glands were dissected free from the submaxillary gland (Pel Freeze, Rogers, AK, U.S.A.) and homogenized as above in ice-cold homogenizing buffer containing (mM): sucrose 250; Tris 10, EDTA 0.002 at pH 7.5 until a uniform homogenate was observed. Membranes were then prepared and stored as described above.

Protein content was determined with the Bio-Rad protein assay (Bio-Rad Laboratories, Richmond, CA, U.S.A.) using the method described by Bradford (1976) with bovine serum albumin as standard.

\section{Radioligand binding assay}

All binding assays were incubated in $25 \mathrm{~mm}$ glycylglycine (Bylund, 1985), at $25^{\circ} \mathrm{C}$ for $30 \mathrm{~min}$. Binding was stopped by vacuum filtration using a Brandell cell harvester through Whatman GF/B filters, with three $5 \mathrm{ml}$ washes with ice-cold binding buffer. Radioactivity retained on the filter was determined by liquid scintillation counting in Readysafe scintillation fluid.

For $\left[{ }^{3} \mathrm{H}\right]$-rauwolscine saturation studies, total binding was determined in duplicate tubes containing a predetermined concentration of the radioligand and $100-250 \mu \mathrm{g}$ membrane protein in a total volume of $300 \mu$ l. Nonspecific binding was determined in the presence of $10 \mu \mathrm{M}$ phentolamine. Specific binding was calculated as the difference between total and nonspecific binding. The $K_{\mathrm{D}}$ and $B_{\max }$ were calculated from nonlinear regression with the aid of the AccuFit computer programme (Beckman, Fullerton, CA, U.S.A.).

For competition studies, various concentrations of $\alpha$ adrenoceptor agonists and antagonists were incubated in the presence of the $K_{\mathrm{D}}$ of $\left[{ }^{3} \mathrm{H}\right]$-rauwolscine for the tissue source being examined and $100-250 \mu \mathrm{g}$ membrane protein in a total volume of $300 \mu$ l. $K_{\mathrm{i}}$ values were determined from nonlinear

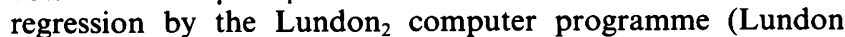
Software Inc., Cleveland, OH, U.S.A.).

\section{Drugs and solutions}

SK\&F 86466 (6-chloro,2, 3, 4, 5-tetrahydro-3-methyl-1H-3benzazepine), SK\&F 104078 (6-chloro-9- [(3-methyl-2butenyl) oxy]-2,3,4,5-tetrahydro-3-methyl-1H-3-benzazepine),
SK\&F 104856 (2-vinyl-7-chloro-3,4,5,6-tetrahydro-4-methylthieno $[4,3,2$ ef] [3] benzazepine and BRL 44408 (2-[(4, 5dihydro-1H-imidazol-2-yl) methyl]-2, 3-dihydro-1-methyl-1Hisoindole) were synthesized by the Medical Chemistry Department of SmithKline Beecham (King of Prussia, PA, U.S.A. or Great Burgh, Surrey, U.K.) BAM1303 (8B[2phenylimidazol-1-yl)methyl-6-methylergoline; Maruko Pharmaceutical Co. Ltd., Nagoya, Japan), ARC-239 (2-[2,4-(omethoxyphenyl)piperazin-1-yl] ethyl-4,4-dimethyl-1,3- $(2 \mathrm{H}, 4 \mathrm{H})$ -isoquinolindione; Karl Thomae, Biberach, Germany) and prazosin (Pfizer, Groton, CT, U.S.A.) were kindly donated by their manufacturers. Sources of reagents were as follows: GIBCO, ST. Louis, MO, U.S.A. (trypsin, DMEM, DPBS, FBS); Dupont New England Nuclear, Wilmington, DE, U.S.A. ([ $\left.{ }^{3} \mathrm{H}\right]$-rauwolscine, $\left.78-86 \mathrm{Ci} \mathrm{mmol}^{-1}\right)$; CIBA, Summit NJ, U.S.A. (phentolamine); Reseach Organics, Cleveland, OH, U.S.A. (glycylglycine); Karl Roth, Karlsruhe, Germany (rauwolscine). All other compounds and reagents were obtained from Sigma, St. Louis, MO, U.S.A.

All compounds were dissolved in the appropriate buffer with the exception of ARC 239 which was dissolved in $0.1 \mathrm{~N}$ $\mathrm{HCl}$ and immediately diluted in buffer, and BAM 1303 which was dissolved in ethanol. The maximal ethanol concentration in the assay medium was $1 \%$. This concentration was shown to have no effect on the binding of $\left[{ }^{3} \mathrm{H}\right]$-rauwolscine.

\section{Results}

Representative saturation curves and Scatchard plots for $\left[{ }^{3} \mathrm{H}\right]$-rauwolscine in Y79 cells and rat sublingual gland are shown in Figure 1. Although characterization of $\alpha_{2}$-adrenoceptors has previously been reported in rat submaxillary gland (Michel et al., 1989), we found that when the sublingual gland was separated by dissection from the total submaxillary gland' obtained from the supplier, essentially all of the specific $\left[{ }^{3} \mathrm{H}\right]$-rauwolscine binding was to the sublingual component (data not shown). This may be reflected in our

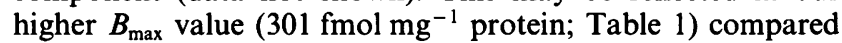
to the value obtained by Michel et al. (1989) in the total submaxillary gland $\left(137 \mathrm{fmol}^{-1}\right.$ protein). $K_{\mathrm{D}}$ and $B_{\max }$ values for $\left[{ }^{3} \mathrm{H}\right]$-rauwolscine binding to HT29, HG108-15 and OK cells are also presented in Table 1 . From Table 1 it is apparent that (1) the receptor density in the Y79 cells is substantially lower than that in the other systems and (2) the affinity of $\left[{ }^{3} \mathrm{H}\right]$-rauwolscine for the binding sites in $\mathrm{OK}$ and Y79 cells is higher than in the other preparations. In all systems examined the specific binding of $\left[{ }^{3} \mathrm{H}\right]$-rauwolscine represented at least $70 \%$ of the total binding to the tissue homogenate.

The potency of a series of 10 compounds in inhibiting the binding of $\left[{ }^{3} \mathrm{H}\right]$-rauwolscine to the five tissue sources is shown in Table 2. The compounds examined included eight antagonists, plus the partial agonists, oxymetazoline and clonidine. The selectivity previously reported for prazosin, ARC 239 and SK\&F 104856 in NG108-15 versus HT29 cells; and, conversely, oxymetazoline and BRL 44408 in HT29 versus NG108-15 cells is confirmed by our data. Consistent with the $K_{\mathrm{D}}$ values for $\left[{ }^{3} \mathrm{H}\right]$-rauwolscine as determined by saturation analysis, the $K_{\mathrm{i}}$ for unlabelled rauwolscine was lower in the OK and Y79 cells.

Correlation of drug affinities as inhibitors of $\left[{ }^{3} \mathrm{H}\right]$-rauwolscine binding to the five tissue sources shows a statistically significant relationship only for HT29 cells versus sublingual gland and for Y79 cells versus OK cells (Table 3).

\section{Discussion}

Our data provide additional support for the premise that $\alpha_{2}$-adrenoceptors can be subdivided based on the ability of $\alpha$-adrenoceptor agonists and antagonists to displace $\left[{ }^{3} \mathrm{H}\right]-$ rauwolscine binding. As previously reported (Bylund, 1988) 
the $\left[{ }^{3} \mathrm{H}\right]$-rauwolscine sites on HT29, NG108-15 and OK cells clearly represent three distinct groups. In agreement with Blaxall et al. (1991) we found the affinity of $\left[{ }^{3} \mathrm{H}\right]$-rauwolscine to be highest in the OK cells, although our calculated affinity (as reflected by the $K_{\mathrm{D}}$ for $\left[{ }^{3} \mathrm{H}\right]$-rauwolscine or the $K_{\mathrm{i}}$ for unlabelled rauwolscine as an inhibitor of binding) was about five fold lower than that reported by these investigators. Comparison of our data in the OK and HT29 cells with that of Blaxall et al. (1991) shows, with the exception of oxymetazoline and SK\&F 104078 in the OK cell line, our $K_{\mathrm{i}}$ values to
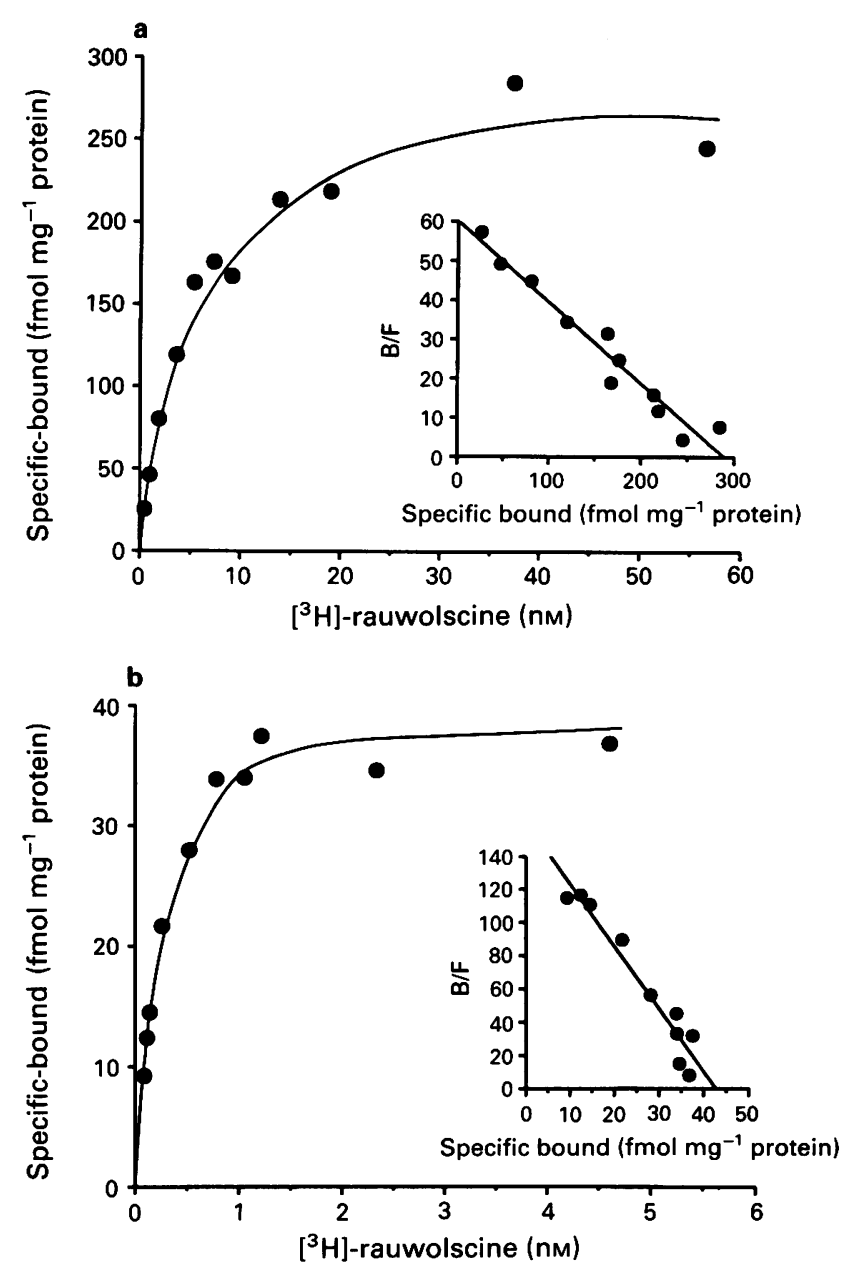

Figure 1 Representative experiments showing saturation curves and Scatchard analyses (inset) for binding of $\left[{ }^{3} \mathrm{H}\right]$-rauwolscine to membrane homogenates of rat sublingual gland (a) and Y79 cells (human retinoblastoma; b). Each point represents the mean of duplicate determinations.
Table 1 Binding parameters of $\left[{ }^{3} \mathrm{H}\right]$-rauwolscine

$\begin{array}{lccc}\text { Tissue } & \mathrm{K}_{d}(\mathrm{nM}) & \begin{array}{c}\mathrm{B}_{\max }\left(\mathrm{fmol} \mathrm{mg} \mathrm{mg}^{-1}\right. \\ \text { protein })\end{array} & S B^{a} \\ & & & \\ \text { HT29 cells }\left(\alpha_{2 \mathrm{~A}}\right) & 1.10 \pm 0.45 & 170 \pm 7 & 87 \\ \text { NG108-15 cells }\left(\alpha_{2 \mathrm{~B}}\right) & 1.37 \pm 0.06 & 235 \pm 20 & 81 \\ \text { OK cells }\left(\alpha_{2 \mathrm{C}}\right) & 0.19 \pm 0.07 & 245 \pm 27 & 93 \\ \text { Rat sublingual gland } & 5.04 \pm 0.37 & 301 \pm 15 & 69 \\ \quad\left(\alpha_{2 \mathrm{D}}\right) & 0.30 \pm 0.10 & 38 \pm 1 & 73 \\ \text { Y79 cells } & & \end{array}$

aspecific binding as $\%$ of total binding.

Values represent mean \pm s.e.mean, derived from at least 2 experiments, each performed in duplicate.

be 3 to 5 fold higher, suggesting the difference may be due to slight changes in experimental methodology. Nevertheless, the relative potencies in these two cell lines of the antagonists tested both by us and Blaxall et al. are nearly identical.

We found the $\alpha_{2}$-adrenoceptor on the rat sublingual gland to be distinct from that on the NG108-15 and OK cells, but not from that on the HT29 (Table 3). Other studies have shown that the cross-subtype correlation for inhibition of $\left[{ }^{3} \mathrm{H}\right]$-rauwolscine binding is closest $(r>0.8$ with regression slopes near unity) when $\alpha_{2 D}$ (bovine pineal, rat submaxillary gland) are compared to $\alpha_{2 A}$ (HT29 cells, chicken pineal) systems (Simmoneaux et al., 1991). Furthermore, most of the agents examined in our study do not discriminate clearly

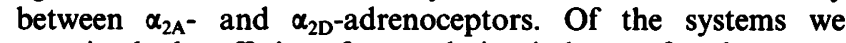
examined, the affinity of rauwolscine is lowest for the receptor of the sublingual gland, as reflected either by the $K_{\mathrm{D}}$ $(5 \mathrm{nM})$ or $K_{\mathrm{i}}(11 \mathrm{nM})$. This relatively low affinity of rauwolscine is characteristic of an $\alpha_{2 \mathrm{D}}$ subtype (Simmoneaux et al., 1991).

Our data in the Y79 cells agrees closely with that reported by Kazmi \& Mishra (1979). Although they assign the $\alpha_{2}$ adrenoceptor in this cell line to the $\alpha_{2 \mathrm{~A}}$ subtype, this assignment was based only on the relative potencies of prazosin and oxymetazoline. When our $K_{\mathrm{i}}$ values in the Y79 cells are compared to the corresponding values in a known $\alpha_{2 \mathrm{~A}}$ system, the HT29 cells, the correlation is poor $(r=0.57$, Table 3). Although the overall correlation of the Y79 and NG108-15 data is slightly better $(r=0.65)$, the three antagonists known to be selective for the $\alpha_{2 B}$ subtype, prazosin, ARC239 and SK\&F 104856 (Gleason \& Hieble, 1991), all are significantly less potent in the Y79 system (Table 2). An excellent correlation is obtained when $K_{\mathrm{i}}$ values in Y79 and OK cells are compared $(r=0.9$; Table 3). Furthermore, the best-fit regression and line of identity between these two systems are superimposable.

It is somewhat disturbing that the only compound deviating from the correlation is BAM1303, reported to be one of the most selective antagonists for $\alpha_{2 C}$-adrenoceptors (Blaxall

Table 2 Potency of drugs as inhibitors of $\left[{ }^{3} \mathrm{H}\right]-$ rauwolscine binding

\begin{tabular}{ccc}
$\mathrm{K}_{i}(\mathrm{nM})^{\mathrm{a}}$ & & \\
& & \\
\multicolumn{1}{c}{$\mathrm{K}$} & Rat sublingual & $Y 79$ \\
& & \\
$41.3 \pm 5.3$ & $420 \pm 84$ & $60.2 \pm 17.9$ \\
$1.98 \pm 0.42$ & $86.2 \pm 25.2$ & $14.8 \pm 5.9$ \\
$24.5 \pm 8.2$ & $10.3 \pm 2.5$ & $10.2 \pm 3.7$ \\
$36.3 \pm 11.3$ & $11.5 \pm 3.3$ & $19.5 \pm 8.1$ \\
$79.9 \pm 4.4$ & $175 \pm 38$ & $125 \pm 29$ \\
$0.26 \pm 0.03$ & $11.1 \pm 3.0$ & $0.54 \pm 0.24$ \\
$187 \pm 24$ & $15.7 \pm 2.3$ & $227 \pm 78$ \\
$8.28 \pm 1.11$ & $5.17 \pm 1.59$ & $3.96 \pm 0.53$ \\
$58.6 \pm 6.7$ & $202 \pm 53$ & $47.2 \pm 7.3$ \\
$59.6 \pm 19.1$ & $117 \pm 33$ & $42.8 \pm 9.9$
\end{tabular}

${ }^{\text {a } V a l u e s}$ are mean \pm s.e.mean and are derived from at least 3 experiments performed in duplicate. 'Data from Gleason \& Hieble (1991). 
Table 3 Correlation of inhibitory potency between tissues

$\begin{array}{lccc}\text { Tissue } & \mathrm{r} & \text { Slope } & \mathrm{P} \\ & & & \\ \text { HT29 cells vs NG108-15 cells }\left(\alpha_{2 \mathrm{~A}} \text { vs } \alpha_{2 \mathrm{~B}}\right) & 0.07 & 0.09 & <0.841 \\ \text { HT29 cells vs OK cells }\left(\alpha_{2 \mathrm{~A}} \text { vs } \alpha_{2 \mathrm{C}}\right) & 0.44 & 0.49 & <0.173 \\ \text { HT29 cells vs Sublingual gland }\left(\alpha_{2 \mathrm{~A}} \text { vs } \alpha_{2 \mathrm{D}}\right) & 0.84 & 1.09 & <0.001 \\ \text { NG108-15 cells vs OK cells }\left(\alpha_{2 \mathrm{~B}} \text { vs } \alpha_{2 \mathrm{C}}\right) & 0.47 & 0.41 & <0.141 \\ \text { NG108-15 vs Sublingual gland }\left(\alpha_{2 \mathrm{~B}} \text { vs } \alpha_{2 \mathrm{D}}\right) & 0.18 & 0.18 & <0.598 \\ \text { OK cells vs Sublingual gland }\left(\alpha_{2 \mathrm{C}} \text { vs } \alpha_{2 \mathrm{D}}\right) & 0.22 & 0.25 & <0.524 \\ \text { HT29 cells vs Y79 cells } & 0.57 & 0.72 & <0.086 \\ \text { NG108-15 cells vs Y79 cells } & 0.65 & 0.60 & <0.044 \\ \text { OK cells vs Y79 cells } & 0.90 & 1.01 & <0.0001 \\ \text { Sublingual gland vs Y79 cells } & 0.56 & 0.50 & <0.095\end{array}$

Values are derived from linear regression analysis of the correlations of the $\log$ of the drug affinities presented in Table 2.

et al., 1991). Nevertheless, in addition to the excellent overall correlation of $K_{\mathrm{i}}$ values, the OK and Y79 cells share several characteristics distinguishing them from the other systems studied: (1) a 5-10 fold lower potency of ARC 239, prazosin and SK\&F 104856 vis-a-vis the NG-108 cells; this difference is consistent with the relative potenties for these antagonists in the OK cells compared with another $\alpha_{2 B}$ system, the neonatal rat lung (Simmoneaux et al., 1991). (2) A higher affinity for rauwolscine (3-20 fold difference for the Y79 cells compared with the NG-108 15, HT29 or rat sublingual preparations). (3) An oxymetazoline affinity intermediate between that observed in the $\alpha_{2 A}$ and $\alpha_{2 B}$ models. Hence, we propose that the Y79 cell line represents an additional example of an

\section{References}

BLAXALL, H.S., MURPHY, T.J., BAKER, J.C., RAY, C. \& BYLUND, D.B. (1991). Characterization of the Alpha-2C adrenergic receptor subtype in the opossum kidney and in the OK cell line. $J$. Pharmacol. Exp. Ther., 259, 323-329.

BRADFORD, M.A. (1976). A rapid and sensitive method for the quantitation of microgram quantities of protein utilizing the principle of protein-dye binding. Anal. Biochem., 72, 248-254.

BYLUND, D.B. (1985). Heterogeneity of $\alpha_{2}$-adrenergic receptors. Pharmacol. Biochem. Behav., 22, 835-843.

BYLUND, D.B. (1988). Subtypes of $\alpha_{2}$-adrenoceptors: pharmacological and molecular biological evidence converge. Trends Pharmacol. Sci., 9, 356-361.

BYLUND, D.B. \& RAY-PRENGER, C. (1989). $\alpha_{2 A}$ and $\alpha_{2 B}$ adrenergic receptor subtypes: attenuation of cyclic AMP production in cell lines containing only one receptor subtype. J. Pharmacol. Exp. Ther., 252, 640-644.

CHHAJLANI, V., RANGEL, N., UHLEN, S. \& WIKBERG, J.E.S. (1991). Identification of an additional gene belonging to the $\alpha_{2}$-adrenergic receptor family in the human genome by PCR. FEBS Lett., 280, $241-244$

FLORDELLIS, C.S., HANDY, D.E., BRESNAHAN, M.R., ZANNIS, V.I. \& GAVRAS, H. (1991). Cloning and expression of a rat brain $\alpha_{2 B}$ adrenergic receptor. Proc. Natl. Acad. Sci. U.S.A., 88, 1019-1023.

GLEASON, M.M. \& HIEBLE, J.P. (1991). Ability of SK\&F 104078 and SK\&F 104856 to identify $\alpha_{2}$-adrenoceptor subtypes in NCB20 cells and guinea pig lung. J. Pharmacol. Exp. Ther., 259, 1124-1132.

GUYER, C.A., HORSTMAN, D.A., WILSON, A.L., CLARK, J.D., CRAGOE, E.J. \& LIMBIRD, L.E. (1990). Cloning, sequencing and expression of the gene encoding the porcine $\alpha_{2}$-adrenergic receptor. J. Biol. Chem., 265, $17307-17317$.

HARRISON, J.K., D'ANGELO, D.D., ZENG, D. \& LYNCH, K.R. (1991) Pharmacological characterization of rat $\alpha_{2}$-adrenergic receptors. Mol. Pharmacol., 40, 407-412.

KAZMI, S.M.I. \& MISHRA, R.K. (1989). Identification of $\alpha_{2}$-adrenergic receptor sites in human retinoblastoma (Y-79) and neuroblastoma (SH-SY5Y) cells. Biochem. Biophys. Res. Commun., 158, $921-928$. $\alpha_{2 \mathrm{C}}$-adrenoceptor.

Based on the ability of mianserin enantiomers to block $\alpha_{2}$-adrenoceptor-mediated inhibition of synaptosomal noradrenaline release (Raiteri et al., 1983), it has been postulated that a functional $\alpha_{2 \mathrm{C}}$-adrenoceptor may be present in the rat cerebral cortex (Blaxall et al., 1991). Our results, showing these receptors to be present in a cell line derived from a human tumour (Reid et al., 1974) provide further support for the premise that the $\alpha_{2 \mathrm{C}}$-adrenoceptor is not limited to the opossum. Further studies, using the selective antagonists now available, will be required to establish the distribution and functional role of this receptor subtype.

LANIER, S.M., DOWNING, S., DUZIC, E. \& HOMCY, C.J. (1991). Isolation of rat genomic clones encoding subtypes of the $\alpha_{2}$ adrenergic receptor. J. Biol. Chem., 266, 10470-10478.

LORENZ, W., LOMASNEY, J.W., COLLINS, S., REGAN, J.W., CARON, M.G. \& LEFKOWITZ, R.J. (1990). Expression of three $\alpha_{2}$ adrenergic receptor subtypes in rat tissues: implications for $\alpha_{2}$ receptor classification. Mol. Pharmacol., 38, 599-603.

MICHEL, A.D., LOURY, D.N. \& WHITING, R.L. (1989). Differences between the $\alpha_{2}$-adrenoceptor in rat submaxillary gland and the $\alpha_{2 \mathrm{~A}}$ and $\alpha_{2 \mathrm{~B}}$ adrenoceptor subtypes. Br. J. Pharmacol., 98, $890-897$.

RAITERI, M., MAURA, G. \& VERSACE, P. (1983). Functional evidence for two stereochemically different $\alpha_{2}$-adrenoceptors regulating central norepinephrine and serotonin release. J. Pharmacol. Exp. Ther., 224, 679-684.

REID, T.W., ALBERT, D.M., RABSON, A.S., RUSSELL, P.,CRAFT, J., CHU, E.W., TRALKA, T.S. \& WILCOX, J.L. (1974). Characteristics of an established cell line of retinoblastoma. J. Natl. Cancer Inst., 53, 347-360.

SIMMONEAUX, V., EBADI, M. \& BYLUND, D.B. (1991). Identification and characterization of $\alpha_{2 D}$ adrenergic receptors in bovine pineal gland. Mol. Pharmacol., 40, 235-241.

UHLEN, S. \& WIKBERG, J.E.S. (1991). Delineation of three pharmacological subtypes of $\alpha_{2}$-adrenoceptor in the rat kidney. $B r . J$. Pharmacol., 104, 657-664.

VOIGT, M.M., MCCUNE, S.K., KANTERMAN, R.Y. \& FELDER, C.C. (1991). The rat $\alpha_{2}-C 4$ adrenergic receptor gene encodes a novel pharmacological subtype. FEBS Lett., 278, 45-50.

WEINSHANK, R.L., ZGOMBICK, J.M., MACCHI, M., ADHAM, N., LICHTBLAU, H., BRANCHEK, T.A. \& HARTIG, P.R. (1990). Cloning, expression and pharmacological characterization of a human $\alpha_{2 B}$ adrenergic receptor. Mol. Pharmacol., 38, 681-688.

(Received January 17, 1992 Revised May 15, 1992 Accepted May 21, 1992) 